
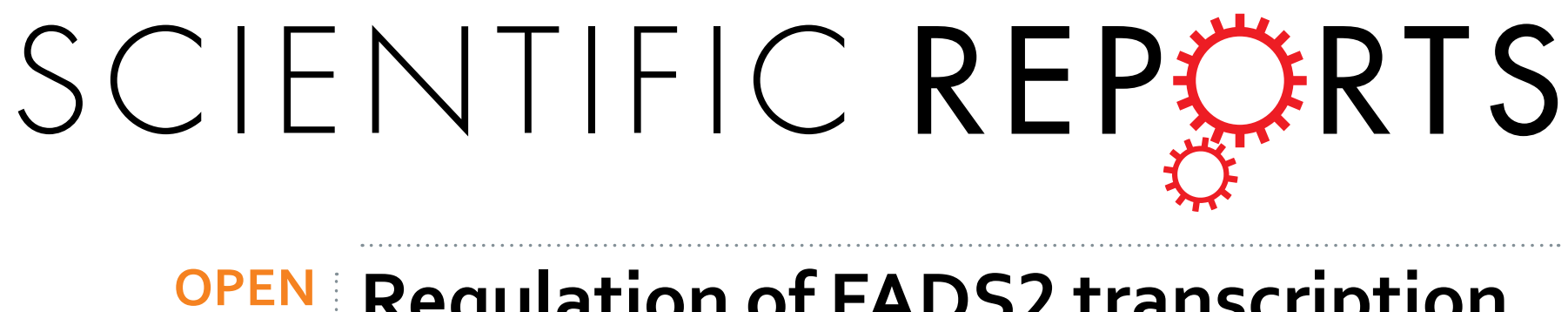

\title{
Regulation of FADS2 transcription by SREBP-1 and PPAR- $\alpha$ influences LC-PUFA biosynthesis in fish
}

Received: 14 June 2016

Accepted: 01 December 2016

Published: 09 January 2017

\section{Xiaojing Dong ${ }^{1}$, Peng Tan ${ }^{1}$, Zuonan $\mathrm{Cai}^{1}{ }^{1}$, Hanlin $\mathrm{Xu}^{1}{ }^{1}$,jingqi $\mathrm{Li}^{1}{ }^{1}$, Wei Ren ${ }^{1}$, Houguo Xu ${ }^{1}$, Rantao Zuo ${ }^{1}$, Jianfeng $\mathrm{Zhou}^{3}$, Kangsen $\mathrm{Mai}^{1,2}$ \& Qinghui $\mathrm{Ai}^{1,{ }^{1}}$}

The present study was conducted to explore the mechanisms leading to differences among fishes in the ability to biosynthesize long-chain polyunsaturated fatty acids (LC-PUFAs). Replacement of fish oil with vegetable oil caused varied degrees of increase in 18-carbon fatty acid content and decrease in n-3 LC-PUFA content in the muscle and liver of rainbow trout (Oncorhynchus mykiss), Japanese seabass (Lateolabrax japonicus) and large yellow croaker (Larimichthys crocea), suggesting that these fishes have differing abilities to biosynthesize LC-PUFAs. Fish oil replacement also led to significantly upregulated expression of FADS2 and SREBP-1 but different responses of the two PPAR- $\alpha$ homologues in the livers of these three fishes. An in vitro experiment indicated that the basic transcription activity of the FADS2 promoter was significantly higher in rainbow trout than in Japanese seabass or large yellow croaker, which was consistent with their LC-PUFA biosynthetic abilities. In addition, SREBP-1 and PPAR- $\alpha$ up-regulated FADS2 promoter activity. These regulatory effects varied considerably between SREBP-1 and PPAR- $\alpha$, as well as among the three fishes. Taken together, the differences in regulatory activities of the two transcription factors targeting FADS2 may be responsible for the different LC-PUFA biosynthetic abilities in these three fishes that have adapted to different ambient salinity.

Decreasing global availability, coupled with the high cost of fish oil, has forced the aquaculture industry to investigate possible alternative sources of dietary lipids. Vegetable oils stand out as the most likely candidates for partial substitutes for fish oils in fish feeds because of their lower price and higher levels of production. Some vegetable oils, such as soybean oil and linseed oil, are considered good alternative lipid sources for salmonids and freshwater fish ${ }^{1-3}$. Although replacing fish oil with vegetable oil generally does not affect the overall health and growth of the fish, most studies have shown that the fish possess reduced levels of long-chain polyunsaturated fatty acids (LC-PUFAs), particularly of DHA and EPA, which are indispensable for their growth and nutrition ${ }^{4-7}$.

In comparison with freshwater fish, marine fish species generally lack the ability to synthesize LC-PUFAs from their 18 -carbon precursor fatty acids ${ }^{8,9}$. However, euryhaline fish commonly show varying levels of capacity to synthesize LC-PUFAs, depending on the ambient salinity ${ }^{10-12}$. Because FADS2 has been shown to catalyse the first limiting step in the LC-PUFA biosynthesis pathway in mammals, special attention has been given to characterization of the FADS2 product ${ }^{13,14}$. Thus, FADS2 has been cloned, and its nutritional regulation has been widely investigated in many fish species ${ }^{15-25}$. Although the expression level of FADS2 generally indicates the capacity for LC-PUFA synthesis in fish ${ }^{16,26}$, the underlying mechanisms by which FADS2 expression is regulated have rarely been reported.

Two transcription factors, SREBP and PPAR, are involved in the regulation of fatty acid biosynthesis in mammals ${ }^{27-33}$, by binding to sterol regulatory elements (SREs) ${ }^{27,34}$ and peroxisome proliferator response elements (PPREs) ${ }^{35}$, respectively. In fish, previous studies have shown that SREBP-1 is related to fatty acid metabolism ${ }^{36,37}$ and that the gene expression of SREBP- 1 and PPAR- $\alpha$ can be regulated by dietary fatty acids ${ }^{33}$. However, it remains unclear whether these two factors are involved in fatty acid biosynthesis by targeting FADS2.

${ }^{1}$ Key Laboratory of Aquaculture Nutrition and Feed (Ministry of Agriculture) and Key Laboratory of Mariculture (Ministry of Education), Ocean University of China, 5 Yushan Road, Qingdao, Shandong 266003, People's Republic of China. ${ }^{2}$ Laboratory for Marine Fisheries and Aquaculture, Qingdao National Laboratory for Marine Science and Technology, Qingdao, Shandong 266003, People's Republic of China. ${ }^{3}$ Key Laboratory of Marine Drugs, Ministry of Education, Ocean University of China, 5 Yushan Road, Qingdao, Shandong 266003, People's Republic of China. Correspondence and requests for materials should be addressed to Q.A. (email: qhai@ouc.edu.cn) 


\begin{tabular}{|c|c|c|c|c|c|c|c|c|c|}
\hline & $\mathrm{RFO}^{1}$ & RFV $^{2}$ & $\mathrm{RVO}^{3}$ & $\mathrm{JFO}^{4}$ & $\mathrm{JFV}^{5}$ & $\mathrm{JVO}^{6}$ & $\mathrm{LFO}^{7}$ & LFV $^{8}$ & $\mathrm{LVO}^{9}$ \\
\hline $\mathrm{IBW}^{10}(\mathrm{~g})$ & $11.36 \pm 0.34$ & $11.24 \pm 0.31$ & $11.14 \pm 0.32$ & $18.66 \pm 0.36$ & $18.55 \pm 0.28$ & $18.59 \pm 1.07$ & $9.00 \pm 0.41$ & $9.09 \pm 0.23$ & $8.69 \pm 0.46$ \\
\hline $\mathrm{FBW}^{11}(\mathrm{~g})$ & $47.68 \pm 1.42$ & $50.95 \pm 2.27$ & $48.36 \pm 1.90$ & $86.83 \pm 1.76^{\mathrm{a}}$ & $76.90 \pm 1.56^{\mathrm{b}}$ & $52.66 \pm 1.15^{\mathrm{c}}$ & $31.51 \pm 1.19^{\mathrm{a}}$ & $27.64 \pm 0.81^{\mathrm{b}}$ & $23.69 \pm 0.77^{\mathrm{c}}$ \\
\hline $\mathrm{SGR}^{12}\left(\mathrm{~g} \mathrm{~d}^{-1}\right)$ & $1.95 \pm 0.04$ & $2.00 \pm 0.07$ & $1.95 \pm 0.06$ & $2.19 \pm 0.02^{\mathrm{a}}$ & $2.01 \pm \pm 0.02^{\mathrm{b}}$ & $1.49 \pm 0.03^{c}$ & $1.79 \pm 0.08^{\mathrm{a}}$ & $1.59 \pm 0.05^{\mathrm{ab}}$ & $1.43 \pm 0.05^{\mathrm{b}}$ \\
\hline $\mathrm{FER}^{13}$ & $0.68 \pm 0.02$ & $0.72 \pm 0.02$ & $0.69 \pm 0.01$ & $0.90 \pm 0.01^{\mathrm{a}}$ & $0.75 \pm 0.02^{\mathrm{b}}$ & $0.46 \pm 0.01^{\mathrm{c}}$ & $0.64 \pm 0.03^{\mathrm{a}}$ & $0.54 \pm 0.02^{\mathrm{b}}$ & $0.52 \pm 0.03^{\mathrm{b}}$ \\
\hline $\mathrm{FI}^{14}\left(\% \mathrm{~d}^{-1}\right)$ & $2.51 \pm 0.05$ & $2.41 \pm 0.02$ & $2.44 \pm 0.03$ & $1.84 \pm 0.01^{\mathrm{a}}$ & $1.74 \pm 0.01^{\mathrm{b}}$ & $1.37 \pm 0.02^{c}$ & $2.52 \pm 0.04$ & $2.64 \pm 0.04$ & $2.56 \pm 0.06$ \\
\hline $\mathrm{SR}^{15}(\%)$ & $98.67 \pm 1.33$ & $98.67 \pm 1.33$ & $94.67 \pm 1.33$ & $78.89 \pm 1.11^{\mathrm{a}}$ & $63.33 \pm 1.92^{b}$ & $65.56 \pm 2.22^{b}$ & $88.33 \pm 0.96^{\mathrm{a}}$ & $67.22 \pm 1.26^{\mathrm{b}}$ & $62.78 \pm 1.82^{\mathrm{b}}$ \\
\hline
\end{tabular}

Table 1. Growth performance and survival rates of three fishes fed experimental diets with vegetable oil instead of fish oil (Mean $\pm \mathbf{S E M})^{*}{ }^{*}$ The statistical analysis was conducted in each fish species. ${ }^{1}$ RFO: $100 \%$ Fish oil as lipid source (control) in rainbow trout. ${ }^{2} \mathrm{RFV}$ : Vegetable oil blend (linseed oil: soya bean oil = 1:1) replacing $50 \%$ of fish oil in rainbow trout. ${ }^{3}$ RVO: $100 \%$ Vegetable oil blend as lipid source in rainbow trout. ${ }^{4} \mathrm{JFO}: 100 \%$ Fish oil as lipid source (control) in Japanese seabass. ${ }^{5} \mathrm{JFV}$ : Vegetable oil blend (linseed oil: soya bean oil $=1: 1$ ) replacing 50\% of fish oil in Japanese seabass. ${ }^{6} \mathrm{JVO}: 100 \%$ Vegetable oil blend as lipid source in Japanese seabass. ${ }^{7}$ LFO: $100 \%$ Fish oil as lipid source (control) in large yellow croaker. ${ }^{8}$ LFV: Vegetable oil blend (linseed oil: soya bean oil $=1: 1$ ) replacing $50 \%$ of fish oil in large yellow croaker. ${ }^{9} \mathrm{LVO}: 100 \%$ Vegetable oil blend as lipid source in large yellow croaker. ${ }^{10} \mathrm{IBW}$ : Initial body weight. ${ }^{11} \mathrm{FBW}$ : Final body weight. ${ }^{12} \mathrm{SGR}=100 \times\left(\ln W_{t}-\ln W_{0}\right) / t .{ }^{13} \mathrm{FER}=\left(W_{t}-W_{0}\right) /$ dry feed intake. ${ }^{14} \mathrm{FI}=100 \times$ dry feed intake $\times 2 /$ $\left(W_{0}+W_{t}\right) / \mathrm{t} .{ }^{15} \mathrm{SR}=100 \times$ final amount of fish/initial amount of fish.

In the present study, a $70 \mathrm{~d}$ feeding experiment was conducted on rainbow trout, Japanese seabass and large yellow croaker to comprehensively compare the effects of different levels of vegetable oil substitution on tissue fatty acid composition and on the expression of genes related to LC-PUFA biosynthesis (FADS2, SREBP-1 and PPAR- $\alpha$ ). Then, an in vitro experiment was conducted to investigate the activity of SREBP-1 and PPAR- $\alpha$ in regulating the expression of the FADS2 gene promoter.

\section{Results}

Growth and survival performance. In rainbow trout, partial or total replacement of fish oil with vegetable oil had no significant effects on SGR, FER, SR and FI compared with the control group. In Japanese seabass, however, increasing the level at which fish oil was replaced with vegetable oil significantly decreased the SGR, FER, FI and SR $(P<0.05)$, although the survival rate showed no significant difference between the FV and VO groups. For large yellow croaker, SGR, FER and SR were significantly reduced by fish oil substitution; however, no significant difference was observed between the $50 \%$ and $100 \%$ substitutions. Interestingly, fish oil replacement showed no influence on feed intake in large yellow croaker, which was also true with rainbow trout (Table 1).

Fatty acid compositions in the liver and muscle. Vegetable oil substitution caused an increase in 18-carbon fatty acids, such as C18:3n-3 and C18:2n-6, in both the livers and muscles of all three fishes, especially in the liver of large yellow croaker, in which the increases reached 4.5 -fold (from $1.49 \mathrm{mg} / \mathrm{g}$ to $6.74 \mathrm{mg} / \mathrm{g}$ ) and 5 -fold (from $6.8 \mathrm{mg} / \mathrm{g}$ to $34.64 \mathrm{mg} / \mathrm{g}$ ) in the $50 \%$ and $100 \%$ replacement groups, respectively. The fish fed $50 \%$ or $100 \%$ vegetable oil showed significantly lower contents of n-3 LC-PUFAs in the muscle and liver than did the fish fed fish oil. The decrease was greatest in large yellow croaker; for example, C20:5n-3 content in muscle decreased from $2.58 \mathrm{mg} / \mathrm{g}$ (FO) to $0.84 \mathrm{mg} / \mathrm{g}$ (FV) and $0.15 \mathrm{mg} / \mathrm{g}$ (VO). However, no significant difference was observed in the C22:6n-3 content of the muscle between rainbow trout fed 50\% vegetable oil and those fed $100 \%$ fish oil (Tables 2 and 3 ).

Cloning and characterization of the promoter and cDNA. The upstream sequences adjacent to the translation start codon of FADS2 in rainbow trout and large yellow croaker were cloned by genome walking, and the fragments were $1479 \mathrm{bp}$ and $996 \mathrm{bp}$ in length, respectively. The promoter sequence of Japanese seabass was published in our previous study ${ }^{24}$. Alignment analysis showed that the FADS2 promoters of rainbow trout, Japanese seabass and large yellow croaker possess transcription factor binding elements including those for nuclear factor Y (NF-Y) and SRE, as in European sea bass and Atlantic salmon, but they lack Sp1 elements (Fig. 1).

The full lengths of the putative SREBP-1 cDNAs from rainbow trout (GenBank accession number: KP342261) and large yellow croaker (GenBank accession number: KP342262) were 4220 bp and 3750 bp in length, respectively, each encoding a protein with high identity to mammalian SREBP-1. The deduced amino acid sequence displayed the typical structure of SREBP, i.e., the bHLH-Zip domain. Alignment analysis of the N-terminal protein sequence showed that SREBP-1 in fish was more similar in length to human SREBP-1a than to SREBP-1c (Fig. S1). The phylogenetic tree showed that fish species clustered together and formed a sister group to the branch for mammals and chicken (Fig. S2).

In the present study, a new putative PPAR- $\alpha$ cDNA (GenBank accession number: KP342260, named PPAR- $\alpha 2$ here) from rainbow trout was cloned that differed from the previously reported one (GenBank accession number: NM_001197211, named PPAR- $\alpha 1$ here) (Fig. S3). The deduced protein sequences of PPAR- $\alpha 2$ from rainbow trout displayed the typical structure of PPAR, i.e., contained a C4-type zinc finger and a ligand-binding domain (Fig. S3). The phylogenetic tree of PPAR- $\alpha$ was obviously divided into two branches, each harbouring one PPAR- $\alpha$ isoform for the fish possessing two sequences, except for rainbow trout (Fig. 2). 


\begin{tabular}{|c|c|c|c|c|c|c|c|c|c|}
\hline Fatty acid & $\mathrm{RFO}^{1}$ & RFV $^{2}$ & $\mathrm{RVO}^{3}$ & $\mathrm{JFO}^{4}$ & $\mathrm{JFV}^{5}$ & $\mathrm{JVO}^{6}$ & $\mathrm{LFO}^{7}$ & LFV $^{8}$ & LVO $^{9}$ \\
\hline C14:0 & $1.09 \pm 0.00^{\mathrm{a}}$ & $0.75 \pm 0.00^{\mathrm{b}}$ & $0.75 \pm 0.02^{\mathrm{b}}$ & $1.09 \pm 0.00^{\mathrm{a}}$ & $0.79 \pm 0.01^{\mathrm{c}}$ & $0.86 \pm 0.02^{\mathrm{b}}$ & $1.76 \pm 0.08^{\mathrm{a}}$ & $1.20 \pm 0.03^{\mathrm{b}}$ & $0.78 \pm 0.01^{\mathrm{c}}$ \\
\hline C16:0 & $4.35 \pm 0.00^{\mathrm{a}}$ & $3.41 \pm 0.18^{\mathrm{b}}$ & $3.21 \pm 0.09^{\mathrm{b}}$ & $2.95 \pm 0.18^{\mathrm{a}}$ & $1.90 \pm 0.07^{\mathrm{b}}$ & $2.22 \pm 0.07^{\mathrm{b}}$ & $7.17 \pm 0.43^{\mathrm{a}}$ & $6.04 \pm 0.29^{\mathrm{a}}$ & $4.24 \pm \pm 0.38^{\mathrm{b}}$ \\
\hline C18:0 & $1.40 \pm 0.01$ & $1.36 \pm 0.12$ & $1.59 \pm 0.00$ & $1.50 \pm \pm 0.06^{\mathrm{a}}$ & $1.08 \pm 0.03^{\mathrm{b}}$ & $1.44 \pm 0.04^{\mathrm{a}}$ & $2.98 \pm 0.09$ & $3.01 \pm 0.31$ & $2.48 \pm 0.22$ \\
\hline$\sum \mathrm{SFA}^{10}$ & $6.84 \pm 0.02^{\mathrm{a}}$ & $5.53 \pm 0.30^{\mathrm{b}}$ & $5.55 \pm 0.09^{\mathrm{b}}$ & $5.54 \pm 0.25^{\mathrm{a}}$ & $3.78 \pm 0.10^{c}$ & $4.52 \pm 0.11^{\mathrm{b}}$ & $11.90 \pm 0.51^{\mathrm{a}}$ & $10.25 \pm 0.61^{\mathrm{a}}$ & $7.51 \pm 0.59^{\mathrm{b}}$ \\
\hline C16:1 & $0.96 \pm 0.09^{\mathrm{a}}$ & $0.49 \pm 0.04^{\mathrm{b}}$ & $0.29 \pm 0.01^{\mathrm{b}}$ & $0.41 \pm 0.06^{\mathrm{a}}$ & $0.24 \pm 0.03^{\mathrm{b}}$ & $0.15 \pm 0.01^{b}$ & $2.51 \pm 0.53^{\mathrm{a}}$ & $1.33 \pm 0.19^{\mathrm{ab}}$ & $0.38 \pm 0.05^{\mathrm{b}}$ \\
\hline C18:1 & $3.40 \pm 0.43^{\mathrm{ab}}$ & $4.48 \pm 0.28^{\mathrm{a}}$ & $2.30 \pm 0.10^{\mathrm{b}}$ & $1.99 \pm 0.39$ & $1.76 \pm 0.18$ & $2.03 \pm 0.09$ & $8.66 \pm 0.53^{a}$ & $7.97 \pm 0.68^{\mathrm{a}}$ & $4.64 \pm 0.71^{\mathrm{b}}$ \\
\hline$\sum$ MUFA $^{11}$ & $4.36 \pm 0.52^{\mathrm{a}}$ & $4.97 \pm 0.26^{\mathrm{a}}$ & $2.59 \pm 0.10^{\mathrm{b}}$ & $2.40 \pm 0.44$ & $2.00 \pm 0.18$ & $2.18 \pm 0.10$ & $11.18 \pm 0.64^{\mathrm{a}}$ & $9.31 \pm 0.86^{\mathrm{a}}$ & $5.01 \pm 0.71^{\mathrm{b}}$ \\
\hline C18:2n-6 & $2.58 \pm 0.57^{\mathrm{b}}$ & $5.39 \pm 0.44^{\mathrm{a}}$ & $5.61 \pm 0.31^{\mathrm{a}}$ & $1.89 \pm 0.43^{\mathrm{b}}$ & $2.44 \pm 0.38^{\mathrm{b}}$ & $4.46 \pm 0.27^{\mathrm{a}}$ & $7.41 \pm 0.04^{\mathrm{b}}$ & $11.85 \pm 0.46^{\mathrm{a}}$ & $14.55 \pm 1.24^{\mathrm{a}}$ \\
\hline C20:4n-6 & $0.20 \pm 0.01^{\mathrm{a}}$ & $0.14 \pm 0.00^{\mathrm{b}}$ & $0.11 \pm 0.01^{b}$ & $0.22 \pm 0.02^{\mathrm{a}}$ & $0.17 \pm 0.01^{\mathrm{ab}}$ & $0.14 \pm 0.01^{\mathrm{b}}$ & $0.28 \pm 0.04^{\mathrm{a}}$ & $0.16 \pm 0.01^{\mathrm{b}}$ & $0.10 \pm 0.00^{\mathrm{b}}$ \\
\hline$\sum \mathrm{n}-6$ PUFA $^{12}$ & $2.78 \pm 0.59^{\mathrm{b}}$ & $5.53 \pm 0.44^{\mathrm{a}}$ & $2.72 \pm 0.31^{\mathrm{b}}$ & $2.11 \pm 0.40^{\mathrm{b}}$ & $2.62 \pm 0.38^{\mathrm{b}}$ & $4.60 \pm 0.27^{\mathrm{a}}$ & $7.70 \pm 0.04^{\mathrm{b}}$ & $12.01 \pm 0.47^{\mathrm{a}}$ & $14.65 \pm 1.24^{\mathrm{a}}$ \\
\hline C18:3n-3 & $0.30 \pm 0.03^{b}$ & $1.14 \pm 0.26^{\mathrm{a}}$ & $0.95 \pm 0.09^{\mathrm{a}}$ & $0.27 \pm 0.06^{c}$ & $0.66 \pm 0.03^{b}$ & $1.21 \pm \pm 0.11^{\mathrm{a}}$ & $0.54 \pm 0.22^{\mathrm{b}}$ & $4.59 \pm 0.59^{\mathrm{a}}$ & $5.76 \pm 1.51^{\mathrm{a}}$ \\
\hline C20:5n-3 & $0.82 \pm 0.10^{\mathrm{a}}$ & $0.47 \pm 0.05^{\mathrm{b}}$ & $0.12 \pm 0.00^{c}$ & $0.64 \pm 0.05^{\mathrm{a}}$ & $0.44 \pm 0.04^{\mathrm{b}}$ & $0.18 \pm 0.01^{c}$ & $2.58 \pm 0.26^{\mathrm{a}}$ & $0.84 \pm 0.06^{\mathrm{b}}$ & $0.15 \pm 0.02^{c}$ \\
\hline C22:6n-3 & $5.24 \pm 0.32^{\mathrm{a}}$ & $4.59 \pm 0.21^{\mathrm{a}}$ & $1.10 \pm 0.10^{\mathrm{b}}$ & $2.28 \pm 0.06^{\mathrm{a}}$ & $1.65 \pm 0.11^{\mathrm{b}}$ & $0.82 \pm 0.06^{\mathrm{c}}$ & $5.25 \pm 0.40^{\mathrm{a}}$ & $2.05 \pm 0.21^{\mathrm{b}}$ & $0.64 \pm 0.11^{\mathrm{c}}$ \\
\hline$\sum \mathrm{n}-3$ PUFA $^{13}$ & $6.36 \pm 0.45^{\mathrm{a}}$ & $6.20 \pm 0.28^{\mathrm{a}}$ & $2.18 \pm 0.18^{\mathrm{b}}$ & $3.18 \pm 0.05^{\mathrm{a}}$ & $2.75 \pm 0.13^{\mathrm{a}}$ & $2.22 \pm 0.15^{\mathrm{b}}$ & $8.38 \pm 0.44$ & $7.47 \pm 0.87$ & $6.54 \pm 1.62$ \\
\hline $\begin{array}{l}\sum \mathrm{n}-3 / \sum \mathrm{n}-6 \\
\text { PUFA }\end{array}$ & $2.39 \pm 0.26^{\mathrm{a}}$ & $1.13 \pm 0.09^{\mathrm{b}}$ & $0.81 \pm 0.03^{b}$ & $1.65 \pm 0.36^{\mathrm{a}}$ & $1.10 \pm 0.19^{\mathrm{ab}}$ & $0.48 \pm 0.01^{\mathrm{b}}$ & $1.09 \pm 0.06^{\mathrm{a}}$ & $0.62 \pm 0.05^{\mathrm{b}}$ & $0.45 \pm 0.09^{\mathrm{b}}$ \\
\hline $\begin{array}{l}\text { Mn-3 LC- } \\
\text { PUFA }\end{array}$ & $6.06 \pm 0.42^{\mathrm{a}}$ & $5.06 \pm 0.25^{\mathrm{a}}$ & $1.23 \pm 0.10^{\mathrm{b}}$ & $2.91 \pm 0.11^{\mathrm{a}}$ & $2.09 \pm 0.15^{\mathrm{b}}$ & $1.01 \pm 0.06^{\mathrm{c}}$ & $7.84 \pm 0.66^{\mathrm{a}}$ & $2.89 \pm 0.28^{b}$ & $0.79 \pm 0.13^{c}$ \\
\hline $\begin{array}{l}\text { Total fatty } \\
\text { acids }\end{array}$ & $21.58 \pm 1.55^{\mathrm{a}}$ & $26.36 \pm 1.97^{\mathrm{a}}$ & $14.43 \pm 0.68^{b}$ & $14.29 \pm 0.68$ & $12.86 \pm 0.71$ & $14.63 \pm 0.81$ & $41.10 \pm 1.63$ & $39.99 \pm 2.38$ & $39.42 \pm 3.76$ \\
\hline
\end{tabular}

Table 2. Muscle fatty acid contents of three fishes fed the experimental diets with vegetable oil instead of fish oil ( $\mathbf{m g} / \mathbf{g}$, Mean $\pm \mathbf{S E M})^{*}$. ${ }^{*}$ Values in the same row with no common superscript letters are significantly different $(P<0.05)$. Some fatty acids that were present in only minor or trace amounts or that were not detected, such as C22:0, C24:0, C14:1, C20:2n-6 and C20:3n-6, are not listed in the table. ${ }^{1}$ RFO: 100\% Fish oil as lipid source (control) in rainbow trout. ${ }^{2} \mathrm{RFV}$ : Vegetable oil blend (linseed oil: soya bean oil $=1: 1$ ) replacing $50 \%$ of fish oil in rainbow trout. ${ }^{3}$ RVO: $100 \%$ Vegetable oil blend as lipid source in rainbow trout. ${ }^{4}$ JFO: $100 \%$ Fish oil as lipid source (control) in Japanese seabass. ${ }^{5} \mathrm{JFV}$ : Vegetable oil blend (linseed oil: soya bean oil = 1:1) replacing $50 \%$ of fish oil in Japanese seabass. ${ }^{6} \mathrm{JVO}: 100 \%$ Vegetable oil blend as lipid source in Japanese seabass. ${ }^{7} \mathrm{LFO}$ : $100 \%$ Fish oil as lipid source (control) in large yellow croaker. ${ }^{8} \mathrm{LFV}$ : Vegetable oil blend (linseed oil: soya bean oil $=1: 1$ ) replacing $50 \%$ of fish oil in large yellow croaker. ${ }^{9} \mathrm{LVO}: 100 \%$ Vegetable oil blend as lipid source in large yellow croaker. ${ }^{10}$ SFA: Saturated fatty acid. ${ }^{11}$ MUFA: Monounsaturated fatty acid. ${ }^{12}$ n- 6 PUFA: n- 6 polyunsaturated fatty acid. ${ }^{13}$ n-3 PUFA: n-3 poly-unsaturated fatty acid.

Gene expression in response to dietary fatty acids. The FADS2 transcript showed significantly higher expression in the livers of the fish fed vegetable oil than in those of the fish fed fish oil. The SREBP-1 transcript also showed higher expression in the fish fed vegetable oil compared with the fish fed fish oil. For PPAR- $\alpha$, replacement of fish oil with vegetable oil significantly up-regulated its expression in the liver of rainbow trout but significantly down-regulated its expression in the liver of Japanese seabass. In large yellow croaker, however, no significant differences between groups were detected. These results showed that among these fishes, the levels of transcription of SREBP- 1 and PPAR- $\alpha$ in the liver respond differently to dietary vegetable oil.

Promoter activity in cells. To determine the promoter activity of FADS2 and the roles of SREBP-1 and PPAR- $\alpha$ in regulating FADS2 promoter activity in the three fishes, HEK293T cells were co-transfected with the FADS2- promoter luciferase reporter plasmid and the SREBP-1 or PPAR- $\alpha$ expression plasmid, using PGL3-Basic and PCS2 + as controls in the dual-luciferase reporter assay.

In HEK293T cells, the promoter activity of FADS2 in rainbow trout was significantly higher than those in Japanese seabass and large yellow croaker, whereas no significant difference was observed between Japanese seabass and large yellow croaker (groups R, J and Y) (Fig. 3). The transcription factor SREBP-1 up-regulated the promoter activity of FADS 2 by 1.58 -fold, 4.57 -fold and 1.59 -fold in rainbow trout, Japanese seabass and large yellow croaker, respectively. The transcription factor PPAR- $\alpha$ up-regulated the promoter activity of FADS2 in rainbow trout and Japanese seabass but not in large yellow croaker. Interestingly, only the newly cloned PPAR- $\alpha$ gene of rainbow trout, i.e., PPAR- $\alpha 2$, showed regulatory activity on the promoter of FADS2 in HEK293T cells (Fig. 3).

\section{Discussion}

The vegetable oils, soybean oil and linseed oil, are relatively rich in 18-carbon fatty acids but have low levels of LC-PUFAs in comparison with fish oil. LC-PUFAs are essential fatty acids for marine fish, and they may lack or have less ability to transform 18-carbon fatty acids into LC-PUFAs. Thus, replacement of fish oil with vegetable oil can negatively affect the growth and survival of marine fishes. The results of this study showed that full replacement did not affect the SGR, FER, FI and SR in rainbow trout (freshwater) but substantially reduced the growth and survival in Japanese seabass (euryhaline) and large yellow croaker (marine). Correspondingly, fishes fed vegetable oil ( $50 \%$ or $100 \%$ ) had high levels of C18:3n-3 and C18:2n-6 but low levels of n-3 LC-PUFAs in their muscles and liver, and this was especially pronounced in the large yellow croaker. Previous studies have demonstrated 


\begin{tabular}{|c|c|c|c|c|c|c|c|c|c|}
\hline Fatty acid & $\mathrm{RFO}^{1}$ & RFV $^{2}$ & $\mathrm{RVO}^{3}$ & $\mathrm{JFO}^{4}$ & $\mathrm{JFV}^{5}$ & $\mathrm{JVO}^{6}$ & $\mathrm{LFO}^{7}$ & LFV $^{8}$ & LVO $^{9}$ \\
\hline C14:0 & $0.49 \pm 0.09^{\mathrm{a}}$ & $0.27 \pm 0.00^{\mathrm{b}}$ & $0.20 \pm 0.00^{\mathrm{b}}$ & $1.42 \pm 0.17$ & $1.56 \pm 0.03$ & $1.70 \pm 0.06$ & $1.56 \pm 0.19^{\mathrm{a}}$ & $0.97 \pm 0.02^{\mathrm{b}}$ & $0.77 \pm 0.07^{b}$ \\
\hline C16:0 & $8.66 \pm 0.10^{\mathrm{a}}$ & $6.61 \pm 0.15^{\mathrm{b}}$ & $6.70 \pm 0.23^{b}$ & $8.57 \pm 0.04^{\mathrm{b}}$ & $8.42 \pm 0.33^{\mathrm{b}}$ & $10.36 \pm 0.37^{\mathrm{a}}$ & $17.43 \pm 0.79^{\mathrm{a}}$ & $18.61 \pm 0.71^{\mathrm{a}}$ & $14.16 \pm 0.32^{\mathrm{b}}$ \\
\hline C18:0 & $5.23 \pm 0.11$ & $5.45 \pm 0.08$ & $4.66 \pm 0.32$ & $4.25 \pm 0.11^{\mathrm{b}}$ & $4.65 \pm 0.23^{\mathrm{b}}$ & $6.81 \pm 0.17^{\mathrm{a}}$ & $10.44 \pm 0.36^{c}$ & $14.35 \pm 0.35^{\mathrm{a}}$ & $12.59 \pm 0.17^{\mathrm{b}}$ \\
\hline$\sum \mathrm{SFA}^{10}$ & $14.38 \pm 0.19^{\mathrm{a}}$ & $12.33 \pm 0.13^{\mathrm{b}}$ & $11.56 \pm 0.30^{\mathrm{b}}$ & $14.25 \pm 0.32^{\mathrm{b}}$ & $14.64 \pm 0.56^{\mathrm{b}}$ & $18.87 \pm 0.48^{\mathrm{a}}$ & $29.01 \pm 1.01^{\mathrm{b}}$ & $33.93 \pm 0.61^{\mathrm{a}}$ & $27.52 \pm 0.22^{\mathrm{b}}$ \\
\hline C16:1 & $1.63 \pm 0.27^{\mathrm{a}}$ & $0.62 \pm 0.01^{\mathrm{b}}$ & $0.38 \pm 0.06^{\mathrm{b}}$ & $2.33 \pm 0.18$ & $2.35 \pm 0.07$ & $2.30 \pm 0.13$ & $5.59 \pm 0.33^{\mathrm{a}}$ & $4.98 \pm 0.19^{\mathrm{ab}}$ & $3.85 \pm 0.35^{\mathrm{b}}$ \\
\hline C18:1 & $6.99 \pm 0.45^{\mathrm{b}}$ & $5.73 \pm 0.25^{\mathrm{b}}$ & $10.48 \pm 0.71^{\mathrm{a}}$ & $10.41 \pm 0.31^{c}$ & $123.23 \pm 0.15^{\mathrm{b}}$ & $32.08 \pm 0.61^{\mathrm{a}}$ & $24.55 \pm 0.89^{c}$ & $28.81 \pm 0.34^{\mathrm{b}}$ & $32.30 \pm 0.09^{\mathrm{a}}$ \\
\hline$\sum$ MUFA $^{11}$ & $8.63 \pm 0.40^{\mathrm{b}}$ & $6.35 \pm 0.24^{c}$ & $10.86 \pm 0.77^{\mathrm{a}}$ & $12.74 \pm 0.49^{c}$ & $25.58 \pm 0.22^{\mathrm{b}}$ & $34.27 \pm 0.68^{\mathrm{a}}$ & $30.13 \pm 1.10^{\mathrm{b}}$ & $33.79 \pm 0.53^{\mathrm{a}}$ & $36.15 \pm 0.27^{\mathrm{a}}$ \\
\hline C18:2n-6 & $3.04 \pm 0.45^{\mathrm{b}}$ & $3.42 \pm 0.11^{\mathrm{b}}$ & $6.18 \pm 0.21^{\mathrm{a}}$ & $3.33 \pm 0.29^{\mathrm{b}}$ & $2.66 \pm 0.35^{\mathrm{b}}$ & $5.40 \pm 0.39^{\mathrm{a}}$ & $6.80 \pm 0.40^{c}$ & $15.28 \pm 0.29^{\mathrm{b}}$ & $34.64 \pm 0.26^{\mathrm{a}}$ \\
\hline C20:4n-6 & $1.87 \pm 0.16^{\mathrm{b}}$ & $1.74 \pm 0.34^{\mathrm{b}}$ & $2.29 \pm 0.41^{\mathrm{a}}$ & $0.10 \pm 0.00^{\mathrm{a}}$ & $0.06 \pm 0.01^{\mathrm{b}}$ & $0.03 \pm 0.00^{c}$ & $0.24 \pm 0.02^{\mathrm{a}}$ & $0.15 \pm 0.01^{\mathrm{b}}$ & $0.05 \pm 0.02^{c}$ \\
\hline$\sum n-6$ PUFA $^{12}$ & $4.91 \pm 0.54^{\mathrm{b}}$ & $5.16 \pm 0.15^{\mathrm{b}}$ & $8.48 \pm 0.23^{\mathrm{a}}$ & $3.43 \pm 0.29^{\mathrm{b}}$ & $2.71 \pm 0.36^{\mathrm{b}}$ & $5.45 \pm 0.38^{\mathrm{a}}$ & $7.04 \pm 0.39^{c}$ & $15.43 \pm 0.30^{\mathrm{b}}$ & $34.69 \pm 0.27^{\mathrm{a}}$ \\
\hline C18:3n-3 & $0.53 \pm 0.09^{\mathrm{b}}$ & $0.51 \pm 0.02^{\mathrm{b}}$ & $1.09 \pm 0.03^{\mathrm{a}}$ & $0.48 \pm 0.08^{\mathrm{b}}$ & $0.70 \pm 0.08^{\mathrm{ab}}$ & $0.84 \pm 0.06^{\mathrm{a}}$ & $1.49 \pm 0.12^{\mathrm{c}}$ & $4.36 \pm 0.30^{\mathrm{b}}$ & $6.74 \pm 0.06^{\mathrm{a}}$ \\
\hline C20:5n-3 & $1.29 \pm 0.13^{\mathrm{a}}$ & $0.72 \pm 0.02^{\mathrm{b}}$ & $0.78 \pm 0.08^{b}$ & $0.20 \pm 0.01^{\mathrm{a}}$ & $0.06 \pm 0.01^{\mathrm{b}}$ & $0.03 \pm 0.00^{c}$ & $1.34 \pm 0.08^{\mathrm{a}}$ & $0.71 \pm 0.06^{\mathrm{b}}$ & $0.14 \pm 0.00^{c}$ \\
\hline C22:6n-3 & $18.60 \pm 1.37^{\mathrm{a}}$ & $13.38 \pm 0.15^{\mathrm{b}}$ & $11.89 \pm 1.64^{\mathrm{b}}$ & $0.65 \pm 0.03^{\mathrm{a}}$ & $0.16 \pm 0.03^{\mathrm{b}}$ & $0.07 \pm 0.01^{b}$ & $2.64 \pm 0.08^{\mathrm{a}}$ & $1.21 \pm 0.07^{\mathrm{b}}$ & $0.27 \pm 0.04^{c}$ \\
\hline$\sum n-3$ PUFA $^{13}$ & $20.42 \pm 1.60^{\mathrm{a}}$ & $14.61 \pm 0.15^{\mathrm{b}}$ & $13.76 \pm 1.73^{\mathrm{b}}$ & $1.33 \pm 0.12^{\mathrm{a}}$ & $1.34 \pm 0.22^{\mathrm{a}}$ & $0.94 \pm 0.05^{\mathrm{b}}$ & $5.47 \pm 0.04^{\mathrm{b}}$ & $6.27 \pm 0.41^{\mathrm{ab}}$ & $7.16 \pm 0.01^{\mathrm{a}}$ \\
\hline $\begin{array}{l}\sum \mathrm{n}-3 / \sum \mathrm{n}-6 \\
\text { PUFA }\end{array}$ & $4.21 \pm 0.31^{\mathrm{a}}$ & $2.84 \pm 0.05^{\mathrm{b}}$ & $1.62 \pm 0.18^{\mathrm{c}}$ & $0.39 \pm 0.00^{\mathrm{a}}$ & $0.34 \pm 0.03^{\mathrm{a}}$ & $0.17 \pm 0.02^{\mathrm{b}}$ & $0.78 \pm 0.04^{\mathrm{a}}$ & $0.41 \pm 0.02^{\mathrm{b}}$ & $0.21 \pm 0.00^{c}$ \\
\hline $\begin{array}{l}\mathrm{n}-3 \mathrm{LC}- \\
\text { PUFA }\end{array}$ & $19.89 \pm 1.50^{\mathrm{a}}$ & $14.10 \pm 0.14^{\mathrm{b}}$ & $12.67 \pm 1.72^{\mathrm{b}}$ & $0.85 \pm 0.03^{\mathrm{a}}$ & $0.22 \pm 0.04^{\mathrm{b}}$ & $0.10 \pm 0.01^{\mathrm{b}}$ & $3.98 \pm 0.15^{\mathrm{a}}$ & $1.92 \pm 0.13^{\mathrm{b}}$ & $0.42 \pm 0.05^{c}$ \\
\hline $\begin{array}{l}\text { Total fatty } \\
\text { acids }\end{array}$ & $43.35 \pm 0.16$ & $42.59 \pm 1.61$ & $45.28 \pm 1.55$ & $34.05 \pm 1.37^{\mathrm{c}}$ & $47.37 \pm 1.30^{\mathrm{b}}$ & $62.20 \pm 0.91^{\mathrm{a}}$ & $79.85 \pm 3.15^{c}$ & $90.13 \pm 3.51^{\mathrm{ab}}$ & $104.86 \pm 4.87^{\mathrm{a}}$ \\
\hline
\end{tabular}

Table 3. Liver fatty acid contents of three fish fed the experimental diets with vegetable oil instead of fish oil ${ }^{1}\left(\mathbf{m g} / \mathbf{g}\right.$, Mean \pm SEM) ${ }^{*}$. ${ }^{*}$ Values in the same row with no common superscript letters are significantly different $(P<0.05)$. Some fatty acids that were present in only minor or trace amounts or that were not detected, such as C22:0, C24:0, C14:1, C20:2n-6 and C20:3n-6, are not listed in the table. ${ }^{1}$ RFO: 100\% Fish oil as lipid source (control) in rainbow trout. ${ }^{2} \mathrm{RFV}$ : Vegetable oil blend (linseed oil: soya bean oil $=1: 1$ ) replacing $50 \%$ of fish oil in rainbow trout. ${ }^{3}$ RVO: $100 \%$ Vegetable oil blend as lipid source in rainbow trout. ${ }^{4}$ JFO: $100 \%$ Fish oil as lipid source (control) in Japanese seabass. ${ }^{5} \mathrm{JFV}$ : Vegetable oil blend (linseed oil: soya bean oil=1:1) replacing $50 \%$ of fish oil in Japanese seabass. ${ }^{6} \mathrm{JVO}: 100 \%$ Vegetable oil blend as lipid source in Japanese seabass. ${ }^{7} \mathrm{LFO}$ : $100 \%$ Fish oil as lipid source (control) in large yellow croaker. ${ }^{8} \mathrm{LFV}$ : Vegetable oil blend (linseed oil: soya bean oil $=1: 1$ ) replacing $50 \%$ of fish oil in large yellow croaker. ${ }^{9} \mathrm{LVO}: 100 \%$ Vegetable oil blend as lipid source in large yellow croaker. ${ }^{10}$ SFA: Saturated fatty acid. ${ }^{11}$ MUFA: Monounsaturated fatty acid. ${ }^{12}$ n- 6 PUFA: n- 6 polyunsaturated fatty acid. ${ }^{13}$ n-3 PUFA: n-3 poly-unsaturated fatty acid.

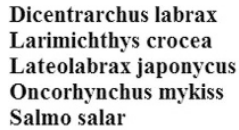

Salmo salar

Dicentrarchus labrax Larimichthys crocea Lateolabrax japonycus Oncorhynchus mykiss Salmo salar

Dicentrarchus labrax Larimichthys crocea Lateolabrax japonycus Oncorhynchus mykiss Salmo salar

Dicentrarchus labrax Larimichthys crocea Lateolabrax japonycus Oncorhynchus mykiss

Salmo salar

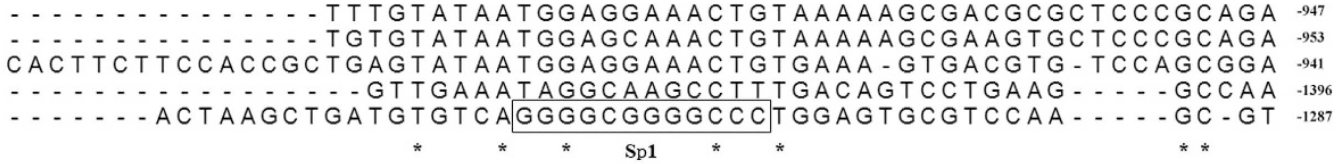

CTGT TTCCGTCTGAGCGCACAGACGACTCTGTAATATTCAGATGAGCTGTTTATTGAGCC -890 CACCTTCCATCTGAGCGCTCAGACGACTCTGTAATATTCAGATGAGCTGTTGATTGAGCC -896 CTGTCTCCGTGTGAGCGCACAGACGACAGTGTGATATTCAGATAAGCTGTTTATTGAGCC -884 TCAGATTAATAGGGACGGACT T T T T T T T - TATACAAT TCGGATAGGCTGTT- - GTGAACC -1330

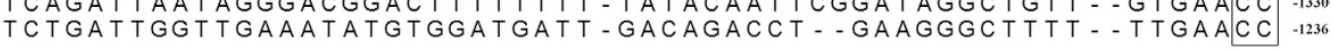
NF-Y NF-Y

TATTGCACATCAGCCAGCGGTCTAGGATATAC - - - TGTACGCCGATTGGCCCAGAAACC -835 TATTGCACATCAGCCAGTGGTCCAGCATGTAC - - - TGTACTCCGATTGGCTCAGAAACC -841 TATTGCACATGAGCCAGTGGTCCAGGATATACCTACTGTGCGCCGATTGGCCCAGAAAGC -825

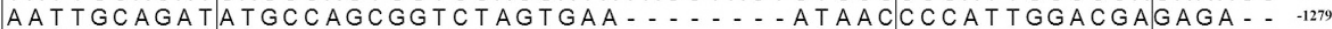
AAT TGCAGATA T GC CAGGGGTCTATTGAA ........ A TAACCCCAT TGGACTAGAGACC 1185 $* * * * * * * * \quad * * * * * * * * * * *$

SRE

C TCGAATGATCGGCTCGGAATTT $\quad-807$ CTCGAATGATCGGCACGGAATTT $\quad-813$ CTCGAATGATC|AGCTCGGAATTT $\quad-798$ C TCGAATGATCGGCATGGAATT- -1253 CTCGAATGATCTGCTTGGTATT $-\quad-1158$

$* * * * * * * * * * * * \quad * * * * *$

Figure 1. Alignment of FADS2 promoter fragments among fish. The numbers indicate sequence position relative to the translation initiation site (ATG). Binding sites are indicated based on previous work from Zheng ${ }^{36}$ and Geay ${ }^{56}$. 


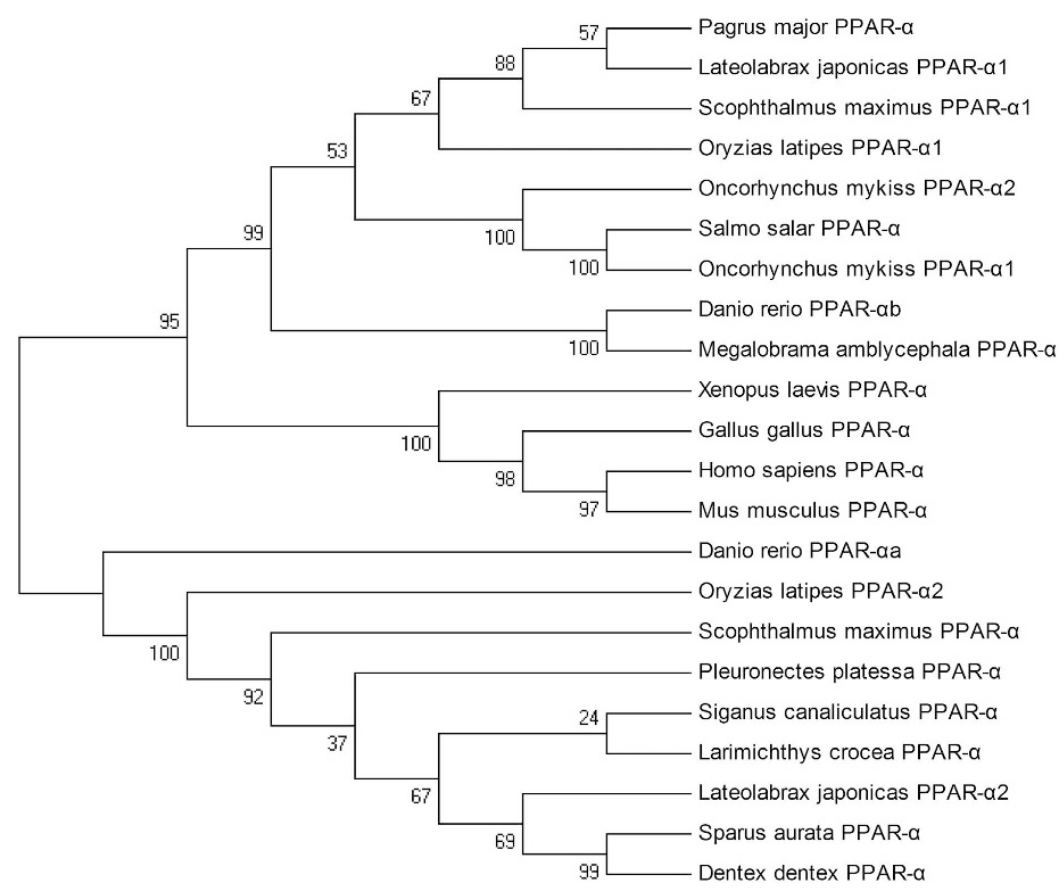

Figure 2. Phylogenetic relationship of the amino acid sequences of PPAR- $\alpha$ from vertebrates and invertebrates.

that marine fish species show less ability to synthesize LC-PUFAs from C18:3n-3 and C18:2n-6 $6^{8,9,22,38-40}$. However, the mechanisms involved in the dietary regulation of LC-PUFA synthesis have rarely been studied in fish to date. FADS2 is a key enzyme catalysing the first rate-limiting step in the biosynthesis of LC-PUFA from C18:3n-3 and C18:2n- 6 and thus is commonly used as an indicator of LC-PUFA biosynthesis ${ }^{16,24,26}$, but the underlying mechanism in fish has been poorly understood.

Both SREBP-1 and PPAR- $\alpha$ are major regulators of fatty acid metabolic genes including those involved in LC-PUFA synthesis. Two forms of mammalian SREBP-1 have been characterized, SREBP-1a and -1c. However, to date, only a single form of the SREBP-1 gene has been characterized in fish ${ }^{33,37,41}$, with no exception for the three fishes investigated in the present study. The alignment analysis of the deduced amino acid sequences showed that the SREBP-1 genes from fish were more similar to human SREBP-1a than to human SREBP-1c, indicating that fish SREBP-1 genes likely only possess functions similar to those of human SREBP-1a transcripts ${ }^{33,37}$. Unlike in mammals, two forms of the PPAR- $\alpha$ gene were characterized in rainbow trout, which was consistent with Japanese seabass, fugu, zebrafish, Japanese medaka, turbot and grass carp ${ }^{33,42,43}$. However, only a single orthologue was found in large yellow croaker, as observed in the olive flounder ${ }^{44}$. The phylogenetic analysis revealed that except in rainbow trout, fish PPAR- $\alpha 1$ and PPAR- $\alpha 2$ were on different branches. It has been hypothesized that gene duplication might have occurred during the evolution of PPAR- $\alpha$, resulting in two orthologues with divergent functions in some fishes ${ }^{33,45}$.

Although not always attaining statistical significance, several studies have shown that replacing fish oil with vegetable oil consistently results in increased FADS2 transcription in fish ${ }^{1,26,39,46-53}$. In the present study, the transcript level of FADS2 was significantly higher in the livers of the fish fed vegetable oil than in those of the fish fed fish oil. Moreover, replacement with vegetable oil significantly up-regulated the transcription level of SREBP-1 in most cases, consistent with previous studies ${ }^{33,54}$. Interestingly, in Japanese seabass fed vegetable oil, the two isotypes of PPAR- $\alpha$ showed different responses, which may indicate that functional differentiation has occurred since the gene duplication ${ }^{33,55}$. In addition, the transcription level of PPAR- $\alpha$ was not significantly influenced by the dietary fatty acids in large yellow croaker. Given that PPAR- $\alpha$ plays important regulatory roles in LC-PUFA biosynthesis in mammals, the different responses of PPAR- $\alpha$ to dietary fatty acids might be responsible for the different LC-PUFA biosynthesis abilities among fishes.

Previous studies suggested that the lack of binding sites for the transcription factor Sp1 may explain the lower activity of the FADS2 promoter in Atlantic cod than in Atlantic salmon ${ }^{36,56}$. Although the FADS2 promoter of rainbow trout showed significantly higher activity than those of the Japanese seabass and large yellow croaker in HEK293T cells, no Sp1 binding site was identified in the promoter region of rainbow trout. Thus, there must be other transcription factors regulating the transcription activity of FADS2. In mammals, transcription of FADS2 is dually regulated by SREBP- 1 and PPAR- $\alpha$, two reciprocal transcription factors for fatty acid metabolism ${ }^{27,57,58}$. In vitro analysis showed that as in mammals, the transcription factor SREBP-1 up-regulated the promoter activity of FADS2 to varying degrees in the three fishes. Moreover, both PPAR- $\alpha 1$ and PPAR- $\alpha 2$ were demonstrated to up-regulate the promoter activity of FADS2 in Japanese seabass, but no such regulatory activity was detected in large yellow croaker. In contrast, in rainbow trout, only PPAR- $\alpha 2$ showed regulatory activity, although both PPAR- $\alpha 1$ and PPAR- $\alpha 2$ were on the same evolutionary branch. Given that the salmonids are still in the process 

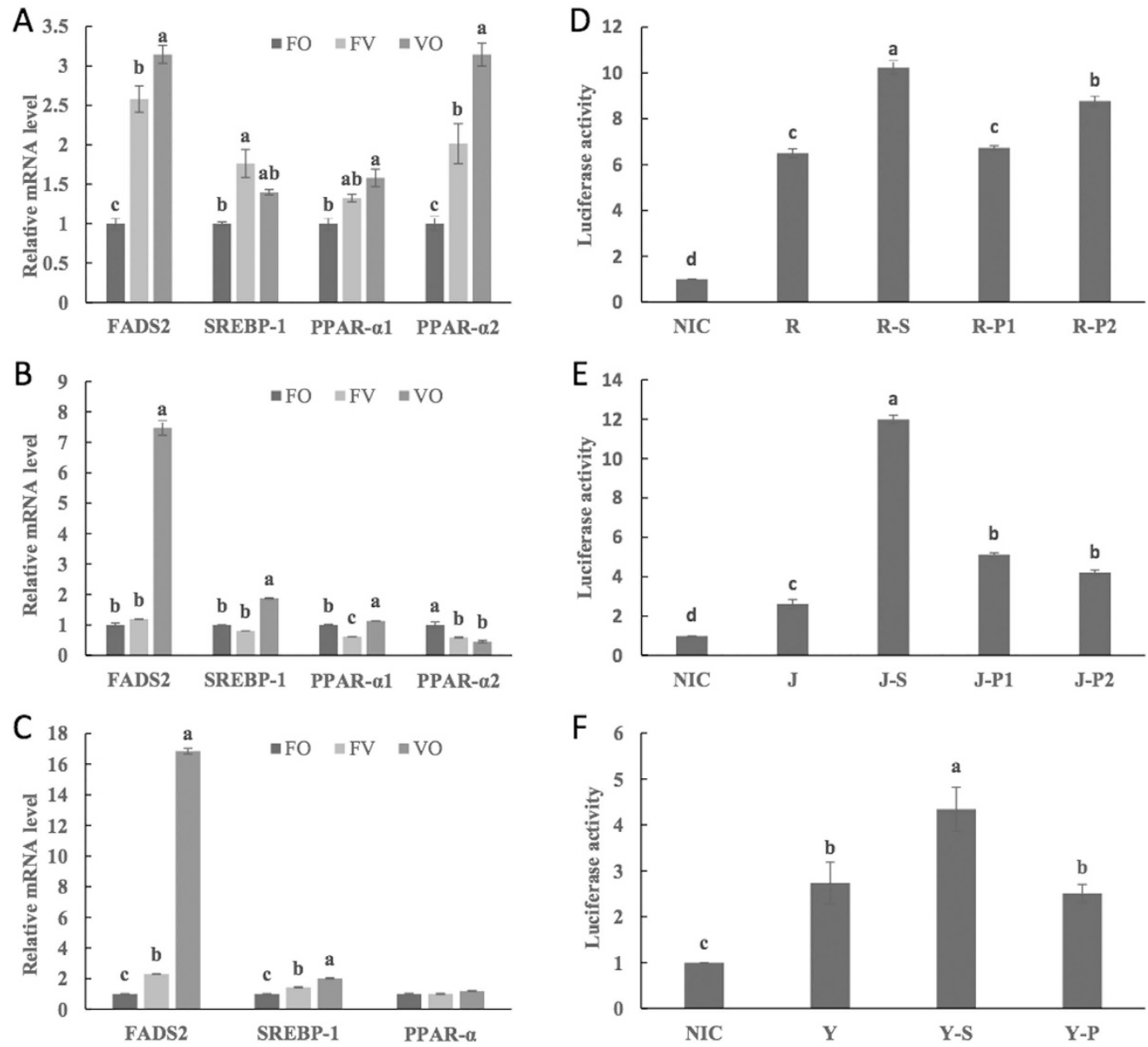

Figure 3. Relative gene transcription levels in the livers of experimental fishes (A-C) and dual-luciferase detection results $(\mathbf{D}-\mathbf{F})$. Gene transcription levels and luciferase activity are presented as the mean \pm SEM $(\mathrm{n}=3)$. The plasmid transfection groups are as follows: NIC: PGL3-Basic + PCS2++ PRL-CMV; R: PGL-RF + PCS2 + + PRL-CMV; R-S: PGL-RF + PCS-RS + PRL-CMV; R-P1: PGL-RF + PCS-RP1 + PRL-CMV; R-P2: PGL-FR + PCS-RP2 + PRL-CMV; J: PGL-JF + PCS2 + + PRL-CMV; J-S: PGL-JF + PCS-JS + PRL-CMV; J-P1: PGL-JF + PCS-JP1 + PRL-CMV; J-P2: PGL-JF + PCS-JP2 + PRL-CMV; Y: PGL-YF + PCS2++ PRLCMV; Y-S: PGL-YF + PCS-YS + PRL-CMV; Y-P: PGL-YF + PCS-YP + PRL-CMV. Different letters above the bars denote significant differences between diet groups at the $P<0.05$ level.

of reverting to a stable diploid state after a genome duplication event ${ }^{59}$, the structural similarity and functional differentiation of the two isotypes of PPAR- $\alpha$ in rainbow trout might suggest that the duplicated PPAR- $\alpha$ gene is still in the process of accumulating mutations.

In conclusion, the present study suggests that two transcription factors, SREBP-1 and PPAR- $\alpha$, are involved in fatty acid biosynthesis via regulating FADS2 and that the differences in their regulatory activity may be responsible for differential LC-PUFA biosynthesis abilities among fishes that have adapted to different ambient salinity.

\section{Materials and Methods}

Ethics statement. The present experimental procedures were carried out in strict accordance with the recommendations in the Guide for the Use of Experimental Animals of Ocean University of China. All animal care and use procedures were approved by the Institutional Animal Care and Use Committee of Ocean University of China (Permit Number: 20001001). Before handling and sacrifice, experimental fish were anesthetized with MS-222 (250 mg/L, Sigma), and all efforts were made to minimize suffering.

Feeding trial. Three isoprotein ( $41 \%$ crude protein) and isolipidic ( $12 \%$ crude lipid) diets were formulated to contain graded levels of vegetable oil blend $(0,50$ and $100 \%)$ by supplementation of soybean oil and linseed oil (Tables 4 and 5). The three artificial diets were designated FO (control), FV and VO.

Rainbow trout was obtained from a commercial farm in Weifang, Shandong, China. Fish similar in size were randomly sorted into tanks that were supplied with a continuous flow of freshwater with continuous aeration. During the entire experiment, the water temperature was kept at $18 \pm 3{ }^{\circ} \mathrm{C}$, with dissolved oxygen at approximately 7-8 mg/L. Large yellow croaker and Japanese seabass were purchased from a local fish farm in Xiangshan Bay, Zhejiang, China. Prior to the beginning of the experiment, fish of similar sizes were randomly grouped and 


\begin{tabular}{|c|c|c|c|}
\hline Ingredients & $\mathrm{FO}^{1}$ & $\mathrm{FV}^{2}$ & $\mathrm{VO}^{3}$ \\
\hline Defatted white fish meal ${ }^{4}$ & 15 & 15 & 15 \\
\hline Soybean meal & 32 & 32 & 32 \\
\hline Casein $^{5}$ & 11 & 11 & 11 \\
\hline Wheat meal & 26 & 26 & 26 \\
\hline Mineral premix ${ }^{6}$ & 2 & 2 & 2 \\
\hline Vitamin premix ${ }^{7}$ & 2 & 2 & 2 \\
\hline Attractant $^{8}$ & 0.3 & 0.3 & 0.3 \\
\hline Mould inhibitor $^{9}$ & 0.1 & 0.1 & 0.1 \\
\hline Lecithin & 2.6 & 2.6 & 2.6 \\
\hline Fish oil & 9 & 4.5 & 0 \\
\hline Soybean oil & 0 & 2.5 & 4.5 \\
\hline Linseed oil & 0 & 2.5 & 4.5 \\
\hline Total & 100 & 100 & 100 \\
\hline \multicolumn{4}{|l|}{ Proximate composition } \\
\hline Crude protein & 41.67 & 41.74 & 41.71 \\
\hline Crude lipid & 12.85 & 12.70 & 12.76 \\
\hline
\end{tabular}

Table 4. Formulation and proximate composition of the experimental diets (\% of dry matter). ${ }^{1} \mathrm{FO}: 100 \%$ Fish oil as lipid source (control). ${ }^{2} \mathrm{FV}$ : Vegetable oil blend (linseed oil: soya bean oil $=1: 1$ ) replacing $50 \%$ of fish oil. ${ }^{3}$ VO: $100 \%$ Vegetable oil blend as lipid source. ${ }^{4}$ Defatted fish meal: $72.1 \%$ Crude protein and $1.4 \%$ crude lipid; white fish meal were defatted with ethanol (fish meal: ethanol $=1: 2$, w:v) at $37^{\circ} \mathrm{C}$ three times. ${ }^{5} \mathrm{Casein}$ : 88\% Crude protein and 1.3\% crude lipid, Alfa Aesar, Avocado Research Chemicals Ltd, UK. ${ }^{6}$ Mineral premix (mg or g kg-1 diet): $\mathrm{CuSO}_{4} \cdot 5 \mathrm{H}_{2} \mathrm{O} 10 \mathrm{mg} ; \mathrm{Na}_{2} \mathrm{SeO}_{3}$ (1\%) $25 \mathrm{mg} ; \mathrm{ZnSO}_{4} \cdot \mathrm{H}_{2} \mathrm{O}, 50 \mathrm{mg} ; \mathrm{CoC}_{12} \cdot 6 \mathrm{H}_{2} \mathrm{O}$ (1\%) $50 \mathrm{mg}$; $\mathrm{MnSO}_{4} \cdot \mathrm{H}_{2} \mathrm{O} 60 \mathrm{mg} ; \mathrm{FeSO}_{4} \cdot \mathrm{H}_{2} \mathrm{O} 80 \mathrm{mg} \mathrm{Ca}\left(\mathrm{IO}_{3}\right)_{2} 180 \mathrm{mg} ; \mathrm{MgSO}_{4} \cdot 7 \mathrm{H}_{2} \mathrm{O} 1200 \mathrm{mg}$; zeolite $18.35 \mathrm{~g}$. ${ }^{7} \mathrm{Vitamin}$ premix (mg or $\mathrm{g} \mathrm{kg}^{-1}$ diet): Vitamin D $5 \mathrm{mg}$; vitamin $\mathrm{K} 10 \mathrm{mg}$ vitamin B12 $10 \mathrm{mg}$ vitamin B6 $20 \mathrm{mg}$; folic acid $20 \mathrm{mg}$; vitamin B1 $25 \mathrm{mg}$; vitamin A $32 \mathrm{mg}$; vitamin B2 $45 \mathrm{mg}$; pantothenic acid $60 \mathrm{mg}$; biotin $60 \mathrm{mg}$; niacin acid $200 \mathrm{mg}$; $\alpha$-tocopherol $240 \mathrm{mg}$; inositol $800 \mathrm{mg}$; ascorbic acid $2000 \mathrm{mg}$; microcrystalline cellulose $16.47 \mathrm{~g}$. ${ }^{8}$ Phagostimulant: Glycine: betaine $=1: 3 .{ }^{9}$ Preservative: Fumarate: calcium propionate $=1: 1$.

\begin{tabular}{|c|c|c|c|}
\hline Fatty acid & FO & FV & VO \\
\hline C14:0 & 0.76 & 0.42 & 0.10 \\
\hline C16:0 & 4.51 & 3.96 & 3.13 \\
\hline C18:0 & 1.63 & 1.72 & 1.71 \\
\hline$\sum \mathrm{SFA}^{2}$ & 6.90 & 6.10 & 4.94 \\
\hline C16:1 & 1.08 & 0.53 & 0.06 \\
\hline C18:1 & 3.59 & 4.58 & 5.47 \\
\hline$\sum$ MUFA $^{3}$ & 4.67 & 5.11 & 5.53 \\
\hline C18:2n-6 & 4.35 & 8.85 & 12.66 \\
\hline C20:4n-6 & 0.12 & 0.07 & 0.04 \\
\hline$\sum n-6$ PUFA $^{4}$ & 4.47 & 8.93 & 12.70 \\
\hline C18:3n-3 & 0.43 & 3.32 & 6.98 \\
\hline$C 20: 5 n-3$ & 1.25 & 0.62 & 0.06 \\
\hline C22:6n-3 & 1.85 & 0.88 & 0.08 \\
\hline$\sum n-3$ PUFA $^{5}$ & 3.53 & 4.82 & 7.12 \\
\hline$\sum n-3 / \sum n-6$ PUFA & 0.79 & 0.54 & 0.56 \\
\hline$\sum \mathrm{n}-3$ LC-PUFA & 3.10 & 1.49 & 0.14 \\
\hline Total fatty acids & 21.18 & 26.82 & 31.09 \\
\hline
\end{tabular}

Table 5. The contents of various fatty acids in the experimental diets $(\mathbf{m g} / \mathrm{g})^{1} .{ }^{1}$ Some fatty acids that were present in only minor or trace amounts or that were not detected, such as C22:0, C24:0, C14:1, C20:2n-6 and C20:3n-6, are not listed in the table. ${ }^{2}$ SFA: Saturated fatty acid. ${ }^{3}$ MUFA: Monounsaturated fatty acid. ${ }^{4} n-6$ PUFA: n-6 poly-unsaturated fatty acid. ${ }^{5} n-3$ PUFA: $n-3$ poly-unsaturated fatty acid.

reared in floating sea cages for one week. During the experiment, all environmental parameters were the same as in the practical cultivation environment; i.e., the temperature was $24-29^{\circ} \mathrm{C}$, the salinity was $29-32 \%$, and the dissolved oxygen was approximately $6-7 \mathrm{mg} / \mathrm{L}$.

Each diet was randomly assigned to triplicate tanks or cages. To prevent wasting of dietary pellets, the fish were slowly hand-fed little by little until apparent satiation on the basis of visual observation. The fish were fed twice daily, at 08:00 and 17:00, for 10 weeks. 


\begin{tabular}{|c|c|c|c|}
\hline Species & Gene & Primer & Sequence $\left(5^{\prime}-3^{\prime}\right)$ \\
\hline \multirow{10}{*}{ Rainbow trout } & \multirow{2}{*}{ SREBP-1 } & RS-F & CAAGCTGCCCATCAACCGTA \\
\hline & & RS-R & GGCCACCAGGTCTTTAAGCTC \\
\hline & \multirow{2}{*}{ PPAR- $\alpha 1$} & RP1-F & TCCCCCAGTCCATCGACGGTGACA \\
\hline & & RP1-R & GAGAACTCCTCCAGCCCTGCAGCT \\
\hline & \multirow{2}{*}{ PPAR- $\alpha 2$} & RP2-F & CAGTCGAGTAACTGCTCTGGCT \\
\hline & & RP2-R & ACAGGCGTGAACTCCATAGTGGT \\
\hline & \multirow{2}{*}{ FADS2 } & RFADS2-F & GTCCGTGCTTTGTGTGAGAA \\
\hline & & RFADS2-R & TCAGAGACCCGACAACATCA \\
\hline & \multirow{2}{*}{$\beta$-actin } & R- $\beta$-actin-F & TCCTTCCTCGGTATGGAGTCT \\
\hline & & $\mathrm{R}-\beta$-actin-R & TTACGGATGTCCACGTCACAC \\
\hline \multirow{10}{*}{ Japanese seabass } & \multirow{2}{*}{ SREBP-1 } & JS-F & TGCTATCGGTTCTAACATGGCTAC \\
\hline & & JS-R & AGTGCTCAACAGTCAGATACAGTC \\
\hline & \multirow{2}{*}{ PPAR- $\alpha 1$} & JP1-F & AAGACCAGCACCCCTCCTTTCGT \\
\hline & & JP1-R & CCGAACTTCTGCCTCCCTGTCCT \\
\hline & \multirow{2}{*}{ PPAR- $\alpha 2$} & JP2-F & TTCCAGCTGGCAGAGAGGACGC \\
\hline & & JP2-R & CACCCCACAGCCGGAACCACCT \\
\hline & \multirow{2}{*}{ FADS2 } & JFADS2-F & CCGTCGCGACTGGGTGGATATG \\
\hline & & JFADS2-R & CAGTCCCGGTGCTTCTCGTGG \\
\hline & \multirow{2}{*}{$\beta$-actin } & $\mathrm{J}-\beta$-actin-F & CAACTGGGATGACATGGAGAAG \\
\hline & & $\mathrm{J}-\beta$-actin-R & TTGGCTTTGGGGTTCAGG \\
\hline \multirow{8}{*}{ Large yellow croaker } & \multirow{2}{*}{ SREBP-1 } & YS-F & TCTCCTTGCAGTCTGAGCCAAC \\
\hline & & YS-R & TCAGCCCTTGGATATGAGCCT \\
\hline & \multirow{2}{*}{ PPAR- $\alpha 1$} & YP-F & AAGTGCCTCTCTGTGGGAATGT \\
\hline & & YP-R & TCACCTCTTTCTCCACCATCT \\
\hline & \multirow{2}{*}{ FADS2 } & YFADS2-F & TTCGCTTCCTCTGCTGCTATG \\
\hline & & YFADS2-R & CCAGTCACGGTGCTTCTCG \\
\hline & \multirow{2}{*}{$\beta$-actin } & Y- $\beta$-actin-F & CTACGAGGGTTATGCCCTGCC \\
\hline & & Y- $\beta$-actin-R & TGAAGGAGTAACCGCGCTCTGT \\
\hline
\end{tabular}

Table 6. Primers used in real-time PCR.

Assay of fatty acid composition. The fatty acid composition was determined via gas chromatographymass spectrometry (GC-MS) using a Thermo TRACE 1310 GC-ISQ QD MS mass spectrometer equipped with an Agilent 7890AGC-5975CMS gas chromatograph.

RNA extraction, cDNA synthesis and quantitative real-time PCR. Total RNA was extracted from the liver using RNAiso Plus (TaKaRa Bio, Dalian, China) according to the manufacturer's protocol. Then, $1 \mu \mathrm{g}$ of total RNA was subjected to PrimeScript ${ }^{\circledR}$ RT reagent Kit with gDNA Eraser (TaKaRa Bio) in a $20 \mu l$ volume for reverse transcription and DNA removal.

Real-time PCR was conducted in a quantitative thermal cycler (Eppendorf, Hamburg, Germany). The amplification was performed in a total volume of $25 \mathrm{ml}$, containing $1 \mu \mathrm{l}$ of each primer $(10 \mathrm{mM}), 1 \mu \mathrm{l}$ of the diluted first strand cDNA product, $12.5 \mu \mathrm{l}$ of $2 \times$ SYBR Premix Ex Taq II (TaKaRa Bio) and $9.5 \mu \mathrm{l}$ of sterilized double-distilled water. The primer sequences for $\beta$-actin, FADS2, SREBP-1, PPAR- $\alpha 1$ and PPAR- $\alpha 2$ were designed using Primer Premier 5.0 (Table 6). Each sample was run in triplicate. For each run, PCR controls were assayed and PCR efficiency was measured by the slope of a standard curve using serial dilutions of cDNA. PCR amplification efficiency values ranged between 0.90 and 1.10 in all cases. The gene expression levels of putative FADS2, SREBP-1, PPAR- $\alpha 1$, and PPAR- $\alpha 2$ were determined using the $2^{-\Delta \Delta \mathrm{CT}}$ method $^{60}$.

Luciferase Reporter Assay. The genome-walking experiment was conducted to isolate the promoter sequences of FADS2 of rainbow trout, Japanese seabass and large yellow croaker. Briefly, genomic DNAs were extracted from the liver tissue using the SQ Tissue DNA Kit (Omega Bio-Tek, Norcross, America), and specific reverse primers were designed for each species (Table S1) based on the sequences of rainbow trout (NM_001124287.1), Japanese seabass (JX678842.1) and large yellow croaker (NM_001303363). Three rounds of genome walking were conducted for each species, using the forward primer AP4 supplied in the kit (Takara Bio) according to the manufacturer's instructions.

For cloning the cDNAs of $S R E B P$ and $P P A R$ - $\alpha$, degenerate primers were designed based on highly conserved regions of the genes from other fishes available in the GenBank database. Then, gene-specific primers were further designed (Table S2) to clone the $3^{\prime}$ and $5^{\prime}$ ends by rapid amplification of cDNA ends (RACE) technology using the SMARTer ${ }^{\mathrm{TM}}$ RACE cDNA Amplification Kit (Clontech, Mountain View, America). PCR products were cloned into the pEASY-T1 simple cloning vector (TransGen, Beijing, China) and sequenced by Sangon Biotech (Shanghai, China). 
Similar searches of the cloned cDNA sequences were conducted using Blastn against the NCBI database (www.ncbi.nlm.nih.gov/blast/). Multiple-sequence alignment was carried out using ClustalW, followed by the construction of phylogenetic trees by using the neighbour-joining method in MEGA version 4.0.

For functional analysis, coding sequences of SREBP-1 and PPAR- $\alpha$ from rainbow trout, Japanese seabass and large yellow croaker were sub-cloned into the PCS2 + expression vectors, named PCS-RS, PCS-RP1, PCS-RP2, PCS-JS, PCS-JP1, PCS-JP2, PCS-YS, and PCS-YP. The FADS2 promoters from the three fishes were sub-cloned into the PGL3-Basic vector (Promega, Beijing, China), which does not include a promoter but contains a luciferase reporter gene, and named PGL-RF, PGL-JF and PGL-YF. All recombinant constructs were sequenced to verify the orientation before in vitro experiments in HEK293T cells. (Table S3).

HEK293T cells were maintained in DMEM supplied with $10 \%$ foetal bovine serum. Cells were seeded into 24-well plates. When they reached $60-70 \%$ confluence, the plasmids were transfected into duplicate wells using the Lipofectamine 2000 system (Invitrogen, Carlsbad, America). For each experiment, $600 \mathrm{ng}$ of PCS plasmid, $200 \mathrm{ng}$ of PGL3 plasmid, and $20 \mathrm{ng}$ of the Renilla luciferase reporter plasmid PRL-CMV (Promega) were mixed and transfected at $26^{\circ} \mathrm{C}$.

The cells were cultured for 6 hours, followed by replacement of the transfection medium with fresh medium and further incubation. Luciferase activities were measured $24 \mathrm{~h}$ after the transfection using a dual-luciferase assay kit (Promega). The relative luciferase activities of the promoters were normalized to the control reporter. The final data were from three independent experiments, and each experiment was performed in triplicate.

\section{Calculations and statistical methods.}

$$
\begin{aligned}
& \text { Specific growth rate }(\mathrm{SGR})=100 \times\left(\ln W_{t}-\ln W_{0}\right) / t, \\
& \text { Feed efficiency rate }(\mathrm{FER})=\left(W_{t}-W_{0}\right) / \text { dry feed intake, }
\end{aligned}
$$$$
\text { Feed intake }(\mathrm{FI})=100 \times \text { dry feed intake } \times 2 /\left(W_{0}+W_{t}\right) / t \text {, }
$$

Survival rate $(S R)=100 \times$ final amount of fish/initial amount of fish.

$W_{t}$ and $W_{0}$ are the final and initial body weights, respectively, and $t$ is the duration of the experiment in days.

Differences in the fatty acid composition and gene expression due to the different diets were determined by one-way ANOVA using SPSS 18.0 (SPSS Inc., Chicago, America), and Duncan's multiple range test was used to assess differences among groups. If unequal variance was determined using Levene's test, data were log-transformed before statistical analysis. Data are expressed as the means \pm SEM, and $P$ values of less than 0.05 were considered statistically significant.

\section{References}

1. Bell, J. G. et al. Replacement of fish oil with rapeseed oil in diets of Atlantic salmon (Salmo salar) affects tissue lipid compositions and hepatocyte fatty acid metabolism. J. Nutr. 131, 1535-1543 (2001).

2. Rosenlund, G., Obach, A., Sandberg, M., Standal, H. \& Tveit, K. Effect of alternative lipid sources on long-term growth performance and quality of Atlantic salmon (Salmo salar L.). Aquac. Res. 32, 323-328 (2001).

3. Caballero, M. et al. Impact of different dietary lipid sources on growth, lipid digestibility, tissue fatty acid composition and histology of rainbow trout, Oncorhynchus mykiss. Aquaculture 214, 253-271 (2002).

4. Bell, J. G., Tocher, D. R., Henderson, R. J., Dick, J. R. \& Crampton, V. O. Altered fatty acid compositions in Atlantic salmon (Salmo salar) fed diets containing linseed and rapeseed oils can be partially restored by a subsequent fish oil finishing diet. J. Nutr. 133, 2793-2801 (2003).

5. Bransden, M. P., Carter, C. G. \& Nichols, P. D. Replacement of fish oil with sunflower oil in feeds for Atlantic salmon (Salmo salar L.): effect on growth performance, tissue fatty acid composition and disease resistance. Comp. Biochem. Physiol. B Biochem. Mol. Biol. 135, 611-625 (2003).

6. Menoyo, D., Lopez-Bote, C., Obach, A. \& Bautista, J. Effect of dietary fish oil substitution with linseed oil on the performance, tissue fatty acid profile, metabolism, and oxidative stability of Atlantic salmon. J. Anim. Sci. 83, 2853-2862 (2005).

7. Hixson, S. M., Parrish, C. C. \& Anderson, D. M. Changes in tissue lipid and fatty acid composition of farmed rainbow trout in response to dietary camelina oil as a replacement of fish oil. Lipids 49, 97-111 (2014).

8. Ghioni, C., Tocher, D. R., Bell, M. V., Dick, J. R. \& Sargent, J. R. Low C18 to C20 fatty acid elongase activity and limited conversion of tearidonic acid, 18:4(n-3), to eicosapentaenoic acid, 20:5(n-3), in a cell line from the turbot, Scophthalmus maximus. Biochim. Biophys. Acta 1437, 170-181 (1999).

9. Tocher, D. R. \& Ghioni, C. Fatty acid metabolism in marine fish: low activity of fatty acyl $\Delta 5$ desaturation in gilthead sea bream (Sparus aurata) cells. Lipids 34, 433-440 (1999).

10. Fonseca-Madrigal, J., Bell, J. G. \& Tocher, D. R. Nutritional and environmental regulation of the synthesis of highly unsaturated fatty acids and of fatty-acid oxidation in Atlantic salmon (Salmo salar L.) enterocytes and hepatocytes. Fish Physiol. Biochem. 32, 317-328 (2006).

11. Li, Y. Y. et al. The effects of dietary fatty acids on liver fatty acid composition and Delta(6)-desaturase expression differ with ambient salinities in Siganus canaliculatus. Comp. Biochem. Physiol. B Biochem. Mol. Biol. 151, 183-190, doi: 10.1016/j.cbpb.2008.06.013 (2008).

12. Codabaccus, B. M., Bridle, A. R., Nichols, P. D. \& Carter, C. G. An extended feeding history with a stearidonic acid enriched diet from parr to smolt increases $\mathrm{n}-3$ long-chain polyunsaturated fatty acids biosynthesis in white muscle and liver of Atlantic salmon (Salmo salar L.). Aquaculture 322, 65-73, doi: 10.1016/j.aquaculture.2011.09.014 (2011).

13. Marquardt, A., Stöhr, H., White, K. \& Weber, B. H. cDNA cloning, genomic structure, and chromosomal localization of three members of the human fatty acid desaturase family. Genomics 66, 175-183 (2000).

14. Innis, S. M. Perinatal biochemistry and physiology of long-chain polyunsaturated fatty acids. J. Pediatr. 143, 1-8 (2003).

15. Monroig, O. et al. Multiple genes for functional 6 fatty acyl desaturases (Fad) in Atlantic salmon (Salmo salar L.): gene and cDNA characterization, functional expression, tissue distribution and nutritional regulation. Biochim. Biophys. Acta 1801, 1072-1081, doi: 10.1016/j.bbalip.2010.04.007 (2010) 
16. Tocher, D. R. et al. Highly unsaturated fatty acid synthesis in marine fish: cloning, functional characterization, and nutritional regulation of fatty acyl $\Delta 6$ desaturase of Atlantic cod (Gadus morhua L.). Lipids 41, 1003-1016 (2006).

17. Monroig, O., Tocher, D. R., Hontoria, F. \& Navarro, J. C. Functional characterisation of a Fads2 fatty acyl desaturase with $\Delta 6 / \Delta 8$ activity and an Elovl5 with C16, C18 and C20 elongase activity in the anadromous teleost meagre (Argyrosomus regius). Aquaculture 412, 14-22 (2013).

18. Mohd-Yusof, N. Y., Monroig, O., Mohd-Adnan, A., Wan, K. L. \& Tocher, D. R. Investigation of highly unsaturated fatty acid metabolism in the Asian sea bass, Lates calcarifer. Fish Physiol. Biochem. 36, 827-843, doi: 10.1007/s10695-010-9409-4 (2010).

19. Morais, S., Mourente, G., Ortega, A., Tocher, J. A. \& Tocher, D. R. Expression of fatty acyl desaturase and elongase genes, and evolution of DHA: EPA ratio during development of unfed larvae of Atlantic bluefin tuna (Thunnus thynnus L.). Aquaculture 313, 129-139 (2011).

20. Zheng, X. et al. Physiological roles of fatty acyl desaturases and elongases in marine fish: Characterisation of cDNAs of fatty acyl $\Delta 6$ desaturase and elovl5 elongase of cobia (Rachycentron canadum). Aquaculture 290, 122-131, doi: 10.1016/j.aquaculture.2009.02.010 (2009).

21. González-Rovira, A., Mourente, G., Zheng, X., Tocher, D. R. \& Pendón, C. Molecular and functional characterization and expression analysis of a $\Delta 6$ fatty acyl desaturase cDNA of European Sea Bass (Dicentrarchus labrax L.). Aquaculture 298, 90-100, doi: 10.1016/j. aquaculture.2009.10.012 (2009).

22. Almaida-Pagán, P. F. et al. Effects of total replacement of fish oil by vegetable oils on n-3 and n-6 polyunsaturated fatty acid desaturation and elongation in sharpsnout seabream (Diplodus puntazzo) hepatocytes and enterocytes. Aquaculture 272, 589-598, doi: 10.1016/j.aquaculture.2007.08.017 (2007).

23. Miller, M. R., Nichols, P. D. \& Carter, C. G. Replacement of dietary fish oil for Atlantic salmon parr (Salmo salar L.) with a stearidonic acid containing oil has no effect on omega-3 long-chain polyunsaturated fatty acid concentrations. Comp. Biochem. Physiol. B Biochem. Mol. Biol. 146, 197-206, doi: 10.1016/j.cbpb.2006.10.099 (2007).

24. Xu, H. et al. Regulation of Tissue LC-PUFA Contents, $\Delta 6$ Fatty Acyl Desaturase (FADS2) Gene Expression and the Methylation of the Putative FADS2 Gene Promoter by Different Dietary Fatty Acid Profiles in Japanese Seabass (Lateolabrax japonicus). PLoS One 9, e87726 (2014).

25. Xu, L. et al. Betaine alleviates hepatic lipid accumulation via enhancing hepatic lipid export and fatty acid oxidation in rats fed with a high-fat diet. British Journal of Nutrition 113, 1835-1843, doi: 10.1017/s0007114515001130 (2015).

26. Geay, F. et al. Regulation of FADS2 expression and activity in European sea bass (Dicentrarchus labrax, L.) fed a vegetable diet. Comp. Biochem. Physiol. B Biochem. Mol. Biol. 156, 237-243, doi: 10.1016/j.cbpb.2010.03.008 (2010).

27. Matsuzaka, T. et al. Dual regulation of mouse $\Delta 5$-and $\Delta 6$-desaturase gene expression by SREBP-1 and PPAR $\alpha$. J. Lipid Res. 43, $107-114(2002)$.

28. Kumadaki, S. et al. Mouse Elovl-6 promoter is an SREBP target. Biochem. Biophys. Res. Commun. 368, 261-266 (2008).

29. Qin, Y., Dalen, K. T., Gustafsson, J. A. \& Nebb, H. I. Regulation of hepatic fatty acid elongase 5 by LXRalpha-SREBP-1c. Biochim. Biophys. Acta 1791, 140-147, doi: 10.1016/j.bbalip.2008.12.003 (2009).

30. Muoio, D. M. et al. Fatty acid homeostasis and induction of lipid regulatory genes in skeletal muscles of peroxisome proliferatoractivated receptor (PPAR) alpha knock-out mice. Evidence for compensatory regulation by PPAR delta. J. Biol. Inorg. Chem. 277, 26089-26097, doi: 10.1074/jbc.M203997200 (2002).

31. Mandard, S., Muller, M. \& Kersten, S. Peroxisome proliferator-activated receptor alpha target genes. Cell Mol Life Sci 61, 393-416, doi: 10.1007/s00018-003-3216-3 (2004).

32. Oosterveer, M. H. et al. Fenofibrate simultaneously induces hepatic fatty acid oxidation, synthesis, and elongation in mice. J. Biol. Chem. 284, 34036-34044 (2009).

33. Dong, X. et al. Cloning and characterization of SREBP-1 and PPAR-alpha in Japanese seabass Lateolabrax japonicus, and their gene expressions in response to different dietary fatty acid profiles. Comp. Biochem. Physiol. B Biochem. Mol. Biol. 180, 48-56, doi: 10.1016/j.cbpb.2014.10.001 (2015).

34. Kim, J. B. et al. Dual DNA binding specificity of ADD1/SREBP1 controlled by a single amino acid in the basic helix-loop-helix domain. Mol. Cell. Biol. 15, 2582-2588 (1995).

35. Desvergne, B. \& Wahli, W. Peroxisome proliferator-activated receptors: nuclear control of metabolism 1. Endocr. Rev. 20, 649-688 (1999).

36. Zheng, X., Leaver, M. J. \& Tocher, D. R. Long-chain polyunsaturated fatty acid synthesis in fish: Comparative analysis of Atlantic salmon (Salmo salar L.) and Atlantic cod (Gadus morhua L.) $\Delta 6$ fatty acyl desaturase gene promoters. Comp. Biochem. Physiol. B Biochem. Mol. Biol. 154, 255-263 (2009).

37. Minghetti, M., Leaver, M. J. \& Tocher, D. R. Transcriptional control mechanisms of genes of lipid and fatty acid metabolism in the Atlantic salmon (Salmo salar L.) established cell line, SHK-1. Biochim. Biophys. Acta 1811, 194-202, doi: 10.1016/j. bbalip.2010.12.008 (2011)

38. Mourente, G., Dick, J. R., Bell, J. \& Tocher, D. R. Effect of partial substitution of dietary fish oil by vegetable oils on desaturation and $\beta$-oxidation of $[1-14 C] 18: 3 n-3$ (LNA) and $[1-14 C] 20: 5 n-3$ (EPA) in hepatocytes and enterocytes of European sea bass (Dicentrarchus labrax L.). Aquaculture 248, 173-186 (2005).

39. Vagner, M. \& Santigosa, E. Characterization and modulation of gene expression and enzymatic activity of delta- 6 desaturase in teleosts: A review. Aquaculture 315, 131-143, doi: 10.1016/j.aquaculture.2010.11.031 (2010).

40. Tocher, D. R. Metabolism and functions of lipids and fatty acids in teleost fish. Rev. Fish. Sci. 11, 107-184 (2003b)

41. Thomas, J. K., Wiseman, S., Giesy, J. P. \& Janz, D. M. Effects of chronic dietary selenomethionine exposure on repeat swimming performance, aerobic metabolism and methionine catabolism in adult zebrafish (Danio rerio). Aquat. Toxicol. 130, 112-122 (2013).

42. Robinson-Rechavi, M. et al. Euteleost fish genomes are characterized by expansion of gene families. Genome research 11, 781-788, doi: 10.1101/gr.165601 (2001).

43. Maglich, J. M. et al. The first completed genome sequence from a teleost fish (Fugu rubripes) adds significant diversity to the nuclear receptor superfamily. Nucleic Acids Res. 31, 4051-4058 (2003).

44. Cho, H. K., Kong, H. J., Kim, H. Y. \& Cheong, J. Characterization of Paralichthys olivaceus peroxisome proliferator-activated receptor-alpha gene as a master regulator of flounder lipid metabolism. Gen. Comp. Endocr. 175, 39-47, doi: 10.1016/j. ygcen.2011.08.026 (2012).

45. Jaillon, O. et al. Genome duplication in the teleost fish Tetraodon nigroviridis reveals the early vertebrate proto-karyotype. Nature 431, 946-957 (2004).

46. Bell, J. G. et al. Substituting fish oil with crude palm oil in the diet of Atlantic salmon (Salmo salar) affects muscle fatty acid composition and hepatic fatty acid metabolism. J. Nutr. 132, 222-230 (2002).

47. Tocher, D. R. et al. Polyunsaturated fatty acid metabolism in Atlantic salmon (Salmo salar) undergoing parr-smolt transformation and the effects of dietary linseed and rapeseed oils. Fish Physiol. Biochem. 23, 59-73 (2000).

48. Tocher, D. R., Bell, J., MacGlaughlin, P., McGhee, F. \& Dick, J. R. Hepatocyte fatty acid desaturation and polyunsaturated fatty acid composition of liver in salmonids: effects of dietary vegetable oil. Comp. Biochem. Physiol. B Biochem. Mol. Biol. 130, 257-270 (2001).

49. Tocher, D. R. et al. Effects of diets containing linseed oil on fatty acid desaturation and oxidation in hepatocytes and intestinal enterocytes in Atlantic salmon (Salmo salar). Fish Physiol. Biochem. 26, 157-170 (2002). 
50. Tocher, D. R., Bell, J., McGhee, F., Dick, J. R. \& Fonseca-Madrigal, J. Effects of dietary lipid level and vegetable oil on fatty acid metabolism in Atlantic salmon (Salmo salar L.) over the whole production cycle. Fish Physiol. Biochem. 29, 193-209 (2003).

51. Tocher, D. R., Dick, J. R., MacGlaughlin, P. \& Bell, J. G. Effect of diets enriched in $\Delta 6$ desaturated fatty acids (18:3n-6 and 18:4n-3), on growth, fatty acid composition and highly unsaturated fatty acid synthesis in two populations of Arctic charr (Salvelinus alpinus L.). Comp. Biochem. Physiol. B Biochem. Mol. Biol. 144, 245-253 (2006).

52. Zheng, X., Tocher, D. R., Dickson, C. A., Bell, J. G. \& Teale, A. J. Highly unsaturated fatty acid synthesis in vertebrates: new insights with the cloning and characterization of a $\Delta 6$ desaturase of Atlantic salmon. Lipids 40, 13-24 (2005).

53. Zheng, X. et al. Environmental and dietary influences on highly unsaturated fatty acid biosynthesis and expression of fatty acyl desaturase and elongase genes in liver of Atlantic salmon (Salmo salar). Biochim. Biophys. Acta 1734, 13-24 (2005).

54. Vestergren, A. S. et al. The effect of combining linseed oil and sesamin on the fatty acid composition in white muscle and on expression of lipid-related genes in white muscle and liver of rainbow trout (Oncorhynchus mykiss). Aquacult. Int. 21, 843-859 (2013).

55. Cunha, I. et al. Dynamics of PPARs, fatty acid metabolism genes and lipid classes in eggs and early larvae of a teleost. Comp. Biochem. Physiol. B Biochem. Mol. Biol. 164, 247-258, doi: 10.1016/j.cbpb.2013.01.003 (2013).

56. Geay, F. et al. Characteristics of fads2 gene expression and putative promoter in European sea bass(Dicentrarchus labrax): Comparison with salmonid species and analysis of CpG methylation. Mar. Genom. 5, 7-13 (2012).

57. Nakamura, M. \& Nara, T. Gene regulation of mammalian dasaturases. Biochem. Soc. Trans. 30, 1076-1079 (2002).

58. Nakamura, M. \& Nara, T. Essential fatty acid synthesis and its regulation in mammals. Prostag. Leukotr. Ess. 68, 145-150 (2003).

59. Allendorf, F. W. \& Thorgaard, G. H. Tetraploidy and the evolution of salmonid fishes In Evolutionary Genetics of Fishes (ed Turner, B. J.) 1-53 (Plenum Press, 1984).

60. Livak, K. J. \& Schmittgen, T. D. Analysis of Relative Gene Expression Data Using Real-Time Quantitative PCR and the $2^{-\Delta \Delta C T}$ Method. Methods 25, 402-408 (2001).

\section{Acknowledgements}

We thank Xuedi Du, Yahui Wang, Tianjiao Wang, Jingwei Liu, Yuhui Yuan, Songlin Li, Zhen Wang, Zhuoyi Tang, Kun Cui, Yanjiao Zhang, Huihui Zhou, Wei Xu, and Jifang Li for their assistance in the study. The present study was supported by the National Science Fund for Distinguished Young Scholars of China (31525024), the National Natural Foundation of China (31372541) and the National Basic Research Program of China (2014CB138600).

\section{Author Contributions}

X.J.D., H.G.X., R.T.Z., Q.H.A. and K.S.M. designed the research; X.J.D., P.T., Z.N.C., H.L.X., J.Q.L., W.R. and J.F.Z. conducted the research; X.J.D. and H.G.X. analysed the data and wrote the paper. All authors read and approved the final manuscript.

\section{Additional Information}

Supplementary information accompanies this paper at http://www.nature.com/srep

Competing financial interests: The authors declare no competing financial interests.

How to cite this article: Dong, X. et al. Regulation of FADS2 transcription by SREBP-1 and PPAR- $\alpha$ influences LC-PUFA biosynthesis in fish. Sci. Rep. 7, 40024; doi: 10.1038/srep40024 (2017).

Publisher's note: Springer Nature remains neutral with regard to jurisdictional claims in published maps and institutional affiliations.

(c) (i) This work is licensed under a Creative Commons Attribution 4.0 International License. The images or other third party material in this article are included in the article's Creative Commons license, unless indicated otherwise in the credit line; if the material is not included under the Creative Commons license, users will need to obtain permission from the license holder to reproduce the material. To view a copy of this license, visit http://creativecommons.org/licenses/by/4.0/

(c) The Author(s) 2017 